\title{
ESTUDO E VIABILIDADE DO REVESTIMENTO DE SEMENTES DA SOJA NO PROCESSO DA GERMINAÇÃO A PARTIR DO USO DE POLÍMERO HIDROGEL DE AMIDO DE MILHO ${ }^{1}$
}

\author{
STUDY AND VIABILITY OF SOYBEAN SEED COATINGS IN THE \\ PROCESS OF GERMINATION FROM THE USE OF \\ HYDROGEL POLYMER FROM CORN STARCH
}

\section{Vanessa Matte Cassol ${ }^{2}$, Leonardo Fantinel $^{3}$ e William Leonardo da Silva ${ }^{4}$}

\section{RESUMO}

A agricultura é um dos setores que mais influência na economia brasileira, destacando para a cultura da soja. As condições climáticas influenciam diretamente no desenvolvimento desta cultura, principalmente em relação a precipitações pluviométricas, visto que o excesso e/ou a falta de água podem prejudicar o desenvolvimento da soja. Neste contexto, o presente trabalho tem como objetivo sintetizar um hidrogel superabsorvente e biodegradável para utilizar no revestimento de sementes de soja, a fim de regular a quantidade de água e disponibilizar um ambiente ideal para que a semente possa se desenvolver durante o processo de germinação. Inicialmente, obtiveram-se os hidrogéis de amido 10\% (água/amido), com e sem liofilização/agitação magnética, seguido do ensaio de intumescimento. Em seguida, realizaram-se os ensaios de germinação com as sementes revestidas com os hidrogéis obtidos, comparando-os com um hidrogel. Em relação aos resultados, observou-se que o hidrogel liofilizado com agitação apresentou a melhor eficiência, em relação aos demais hidrogéis sintetizados, atingindo valores superiores a $1.000 \%$, bem como um aumento na área específica e espessura e, assim um aumento na taxa de difusão intermolecular da água sob o hidrogel. Por conseguinte, o revestimento de sementes da soja com polímero hidrogel de amido de milho torna-se uma alternativa potencial na aplicação e melhoria do processo de germinação de grãos.

Palavras-chave: Agricultura, Recobrimento, Biodegradável, Superabsorvente.

\section{ABSTRACT}

Agriculture is one of the sectors that most influence the Brazilian economy, highlighting the soybean culture. The climatic conditions direct influence in the development of this culture, mainly in relation to rainfall precipitations, since the excess and/or lack of water may adversely affect the development of soybeans. In this context, the present work aims at the synthesis of a biodegradable superabsorbent hydrogel for use in the coating of soybean seeds, in order to regulate the amount of water and provide an ideal environment for the seed to develop. Initially, starch hydrogels 10\% were obtained (water/starch), with and without freeze drying/magnetic stirring, followed by hardness and swelling tests. Thereafter, the germination tests were performed with the seeds coated with the obtained hydrogels, comparing with a commercial hydrogel, through the aid of a solution of water and sugar, in order to evaluate the development of the seeds. In relation to the results, it was observed that the lyophilized hydrogel with agitation presented the best efficiency, in relation to the other synthesized hydrogels, reaching values

\footnotetext{
${ }^{1}$ Trabalho Final de Graduação II - TFGII.

${ }^{2}$ Acadêmica do Curso de Engenharia Química - Universidade Franciscana. E-mail: nessakssol@hotmail.com.

${ }^{3}$ Professor do Curso de Engenharia Química - Universidade Franciscana. E-mail: leonardofantinel@ufn.edu.br.

${ }^{4}$ Orientador - Professor do Curso de Engenharia Química - Universidade Franciscana. E-mail: w.silva@ufn.edu.br.
} 
higher than 1,000\%, evidencing its property of a superabsorbent hydrogel. Therefore, the coating of soybean seeds with cornstarch hydrogel polymer becomes a potential alternative in the application and improvement of the grain germination process.

Keywords: Agriculture, Coating, Biodegradable, Superabsorbent.

\section{INTRODUÇÃO}

Com a crescente industrialização e o aumento populacional, o meio ambiente vem sofrendo graves danos, como o acúmulo de contaminantes químicos e biológicos, promovendo mudanças climáticas, como secas, inundações e oscilações bruscas de temperatura (YONEZAWA; MOURA; AOUADA, 2017), afetando diretamente a disponibilidade de alimentos, colocando em risco a produção agrícola brasileira (BARCELLOS et al., 2009). Assim, é indispensável o investimento em novas tecnologias ambientalmente corretas, que garantam a redução destas perdas e promovem o aumento em sua produção, como os hidrogéis naturais ou biodegradáveis, os quais são produtos ecológicos, inovadores e promissores para a agricultura, quando explorados de maneira adequada (YONEZAWA; MOURA; AOUADA, 2017; LI; TSHABALALA; BUSCHLE-DILLER, 2016).

Diante do exposto, o Brasil destaca-se por ser um dos maiores produtores e exportadores de grãos do mundo, influenciando diretamente na sua economia e balança comercial, destacando-se a soja (DALL'AGNOL, 2017) Com as mudanças climáticas observadas nos últimos anos, a procura e o desenvolvimento de novos mecanismos que auxiliam no desenvolvimento desta planta são cada vez mais frequente (BARROS, 2016), visto que é basicamente constituída de água ( $90 \%$ do peso) atuando, assim em praticamente todos os processos fisiológicos e bioquímicos essenciais na fase de germinação e floração (LOPES, 2013). De forma geral, há um crescimento da percepção da importância do uso de sementes de qualidade, possibilitando o emprego de produtos que promovam uma melhoria no desempenho destas no campo e, assim uma alta produção agrícola (FLOSS; FLOSS, 2007).

Assim, a fim de diminuir ou eliminar os problemas relacionados com o processo de germinação, pesquisas estão sendo realizadas utilizando o recobrimento das sementes com polímeros, a fim de aumentar o tamanho e peso das sementes, diminuir as perdas de produtos aplicados na superfície das sementes, melhorar a eficiência e a distribuição dos produtos sobre a semente, reduzir a variação de temperatura e umidade e agregar valor comercial as sementes (BAUDET; PESKER, 2006; PEREIRA et al., 2005). Dentre estes polímeros, o polímero hidrogel vem ganhando relevância, especialmente a respeito da comprovação da sua capacidade de retenção e disponibilidade de água e de sua eficiência como condicionador de solo (DOMICIANO, 2010). Além disso, hidrogéis caracterizam-se por reter entre 20 $100 \%$ de água, em relação ao peso total, enquanto os hidrogéis superabsorventes caracterizam-se para apresentar uma capacidade de retenção de água superior de 100\% (MOTTA,2009). 
Desse modo, os polímeros hidrogéis podem ser considerados como um sistema hidrofílico, onde existe a união de dois ou mais componentes por meio de ligações covalentes e/ou eletrostáticas ordenadas em uma ou mais redes tridimensionalmente estruturadas misturadas por moléculas de determinado solvente, normalmente a água (LIMA, 2008). Além disso, a hidrofilicidade das cadeias e a densidade do agente reticular são fatores que afetam na quantidade de água absorvida pelos hidrogéis (YONEZAWA, 2016).

Além disso, existem forças osmóticas que auxiliam na condução do solvente para dentro da rede polimérica que são contrabalanceados por uma força retrativa (LIMA, 2008). Quando estas forças forem iguais, o hidrogel atinge o estado de equilíbrio, ou seja, de intumescimento onde as redes poliméricas encontram-se mais elásticas (LIMA, 2008). A Figura 1 apresenta a estrutura do hidrogel em meio líquido, enquanto a Figura 2 a comparação entre o hidrogel intumescido e seco, sendo o volume definido como a razão do hidrogel intumescido e a massa do hidrogel seco.

Figura 1 - Representação do comportamento estrutural do hidrogel em meio líquido.

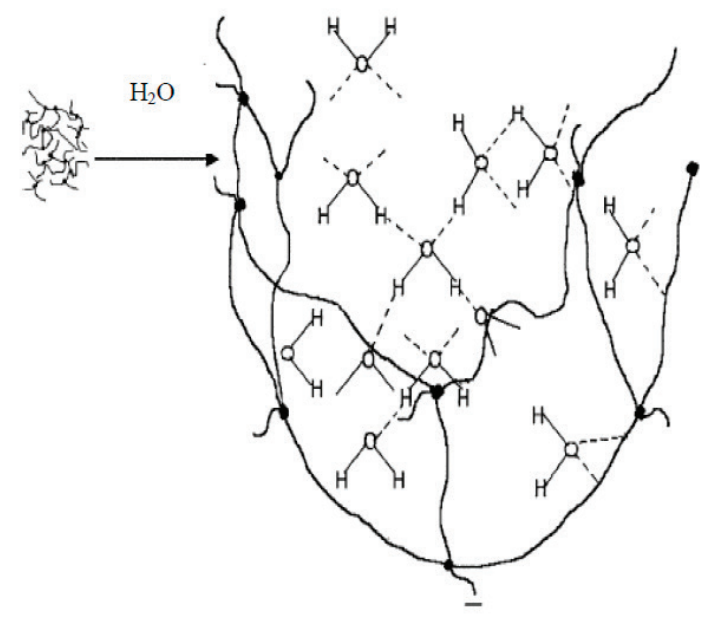

Fonte: LIMA, 2008.

Figura 2 - Representação do hidrogel intumescido e seco.

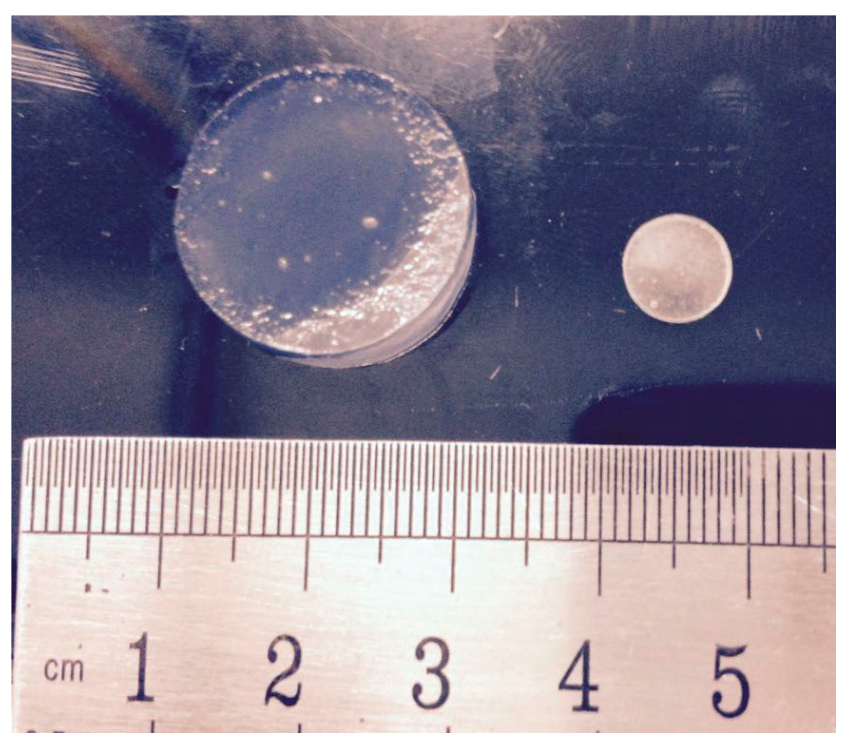

Fonte: YONEZAWA; MOURA; AOUADA, 2017. 
Dentre as vantagens dos polímeros hidrogéis podemos citar: (a) a sua capacidade de regular a disponibilidade de água no solo; (b) o favorecimento na absorção dos nutrientes; (c) redução nas perdas por percolação e lixiviação; (d) aceleração no desenvolvimento de sistemas radiculares, bem como a parte aérea das plantas devido à capacidade de aeração e; (e) drenagem do solo, garantindo uma maior produtividade dos cultivos agrícolas (PRETTO et al., 2016; NETO et al., 2012).

Paralelamente, a busca de precursores para os polímeros hidrogéis vem ganhando destaque, principalmente por materiais biodegradáveis, a fim de favorecer a questão da preservação ambiental, além de proporcionar resultados significativos no cultivo de várias culturas, devido a capacidade de reter quantidades significativas de água, como o hidrogel de amido (YONEZAWA; MOURA; AOUADA, 2017; GUILHERME et al., 2015). Neste caso, o amido de milho surge como um potencial material precursor na síntese destes polímeros, devido a uma série de vantagens, como (ARIETA, 2014): (a) fácil obtenção e custo relativamente barato; (b) facilidade para utilização na agricultura; (c) propriedades de gelatinização e gelificação e; (d) favorável para formação de géis.

Assim, pela grande capacidade da maioria dos polímeros comerciais em reter água e disponibilizá-la de forma gradativa para as plantas, além da redução na lixiviação de nutrientes, a utilização do polímero hidrogel na agricultura tende a ser uma biotecnologia promissora (BRANT, 2008), destacando os hidrogéis de amido de milho pelo seu caráter inovador e sustentável, capaz de suprir determinadas deficiências encontradas na agricultura.

Neste contexto, o presente trabalho tem por objetivo a formulação de um polímero superabsorvente e biodegradável de amido de milho, a fim de viabilizar sua utilização no revestimento de semente de soja e, assim regular a quantidade de água disponível para semente, proporcionando um ambiente ideal para o processo de germinação. Para fins comparativos, um hidrogel comercial (Forth Jardim) será utilizado nos testes de germinação.

\section{MATERIAIS E MÉTODOS}

\section{MATERIAIS UTILIZADOS}

Para os procedimentos de teste branco de germinação, síntese do hidrogel de amido e teste de germinação com o hidrogel, serão utilizados os seguintes materiais, conforme Tabela 1.

Tabela 1 - Materiais utilizados no presente trabalho.

\begin{tabular}{cc}
\hline Material & Procedência \\
\hline \multicolumn{1}{c}{ Teste branco de germinação } \\
\hline Sementes de soja & NA 5909 RG e NS 5959 IPRO \\
Papel para germinação de sementes & Germitest \\
Placas perfuradas & - \\
Água destilada e deionizada & - \\
\hline
\end{tabular}




\begin{tabular}{cc}
\hline \multicolumn{2}{c}{ Síntese do hidrogel de amido } \\
\hline Amido de milho & Comercial \\
\hline Água destilada e deionizada & - \\
\hline \multicolumn{2}{c}{ Teste de germinação com o hidrogel } \\
\hline Sementes de soja & NA 5909 RG e NS 5959 IPRO \\
Papel para germinação de sementes & Germitest \\
Placas perfuradas & - \\
Água destilada e deionizada & - \\
Hidrogel de amido & Comercial (Forth Jardim) \\
\hline
\end{tabular}

Fonte: Construção do Autor.

\section{TESTE INICIAL DE GERMINAÇÃO}

Os ensaios iniciais de germinação foram realizados com as sementes de soja NA 5909 RG e NS 5959 IPRO mediante a adição somente de água, a fim de determinar o potencial máximo de germinação deste lote. Além disso, os mesmos foram em escala laboratorial (Laboratório 204 - UFN), para averiguar as condições ambientais que permitem uma germinação regular das amostras, conforme Manual de Regras de Análise de Sementes do Ministério da Agricultura, Pecuária e Abastecimento (MAPA, 2009).

Inicialmente, as sementes de soja foram homogeneizadas através de agitação manual, seguido da coleta de 400 sementes em repetições de 4 de 100 ou 8 de 50, por meio de placas perfuradas com espaçamento uniforme de $2 \mathrm{~cm}$ entre as sementes, a fim de minimizar a competição e contaminação entre as sementes e plântulas em desenvolvimento. Após, estas sementes foram depositadas sob um substrato de papel úmido (para dar às sementes a quantidade de água necessária para sua germinação) e colocadas para germinar, entre duas folhas de papel para germinação de sementes e enroladas de forma que não ficassem pressionadas, o que impediria a sua aeração.

Em relação a quantidade de água, foi adicionado manualmente um volume equivalente a 2,0 até 3,0 vezes ao peso do substrato e a temperatura mantida na faixa entre 20 a $30^{\circ} \mathrm{C}$, conforme o Manual de Regras de Análise de Sementes do Ministério da Agricultura, Pecuária e Abastecimento (MAPA, 2009). Assim, o primeiro dia de contagem, o qual equivale ao quinto dia após o início do teste, e a partir deste dia foram contados mais oito dias, totalizando 13 dias até o final do teste. Por conseguinte, foi possível avaliar a porcentagem de germinação, ou seja, a proporção no número de sementes que produziu plântulas classificadas como normais, conforme Equação (1).

$$
\text { (\%)germinação }=\frac{\mathrm{n} \text { o de plandulas normais }}{\mathrm{n}^{\mathrm{o}} \text { de sementes da placa perfurada }} \times 100
$$

Desse modo, este teste serveria como parâmetro de comparação com os testes de germinação entre hidrogel sintetizado e o comercial. 
SÍNTESE DO HIDROGEL DE AMIDO

Para a síntese do hidrogel de amido seguiu-se uma metodologia adaptada (DOMICIANO et al., 2010), com e sem o processo de liofilização e agitação magnética. Assim, inicialmente, realizou-se a gelatinização do amido em água destilada e deionizada à $100^{\circ} \mathrm{C}$ com agitação (4 rpm) e sem agitação magnética. Em seguida, a mistura foi congelada por 24 horas, seguida de descongelamento por 2 horas, formando o hidrogel. Na sequência, uma parte deste hidrogel foi novamente congelado e liofilizado (liofilizador de bancada marca Liotop, modelo L-101, Brasil), enquanto uma outra parte passou pelo processo de filtragem por pressão (Millipore Express TM Plus 0,22 $\mu \mathrm{m}$, Fanem Diapump, Portugal), a fim de retirar o excesso de água, seguida da sua secagem (temperatura ambiente por cerca de 72 horas). Destaca-se que os hidrogéis foram preparados na proporção de 10\% em massa (amido/água) e caracterizados, conforme sua cinética de intumescimento. Após esta caracterização, os hidrogéis não liofilizados foram triturados com o auxílio de um moinho (Willye TE-650, Tecinal, Brasil), para aumento da sua área específica auxiliando no processo de revestimento das sementes.

\section{TESTE DE GERMINAÇÃO COM O HIDROGEL}

Após a síntese do hidrogel de amido não liofilizado, testes de germinação foram realizados, a fim de avaliar a eficiência do mesmo em relação a germinação das sementes da soja. Inicialmente, preparou-se uma solução com água destilada e açúcar comercial, na proporção de $100 \mathrm{~mL}$ de água deionizada e 225 gramas de açúcar, onde as sementes foram imersas e agitadas com a solução. Após, estas foram misturadas com o hidrogel de amido (sintetizado e comercial) e, agitadas para sua completa homogeneização. Por fim, destaca-se que os hidrogéis liofilizados não foram utilizados nos testes de germinação devido à pouca quantidade adquirida, pós liofilização.

\section{CARACTERIZAÇÃO DOS HIDROGÉIS DE AMIDO}

Os hidrogéis sintetizados liofilizados e não liofilizados foram caracterizados pela técnica do grau de intumescimento (Q), visto que este está relacionado diretamente com a absorção de água (DOMICIANO et al. 2010). Assim, 0,5 g de amostra (hidrogel) foi imersa em $50 \mathrm{~mL}$ de água deionizada, por tempos pré-determinados $(5,10,15$ e 60 minutos $)$, sendo retirado do meio de intumescimento, removido o excesso de água e pesado. Desse modo, o grau de intumescimento, em relação à amostra seca, pode ser determinado conforme as Equações (2) e (3) (DOMENECH et al., 2004; DOMICIANO et al. 2010). 


$$
Q=\frac{m_{1}}{m_{2}}
$$

Onde:

Q: grau de intumescimento, em relação à amostra seca $(\mathrm{g})$;

$\mathrm{m}_{1}$ : massa de amostra imediatamente após intumescimento em água deionizada ( $\mathrm{g}$ );

$\mathrm{m}_{2}$ : massa inicial de amostra seca $(\mathrm{g})$.

$$
Q=\frac{m_{1}-m_{2}}{m_{2}} \times 100
$$

Onde:

Q: grau de intumescimento (\%);

$\mathrm{m}_{1}$ : massa de amostra imediatamente após intumescimento em água deionizada $(\mathrm{g})$;

$\mathrm{m}_{2}$ : massa inicial de amostra seca $(\mathrm{g})$.

\section{RESULTADOS E DISCUSSÕES}

\section{SÍNTESE DO HIDROGEL DE AMIDO}

A Figura 3a apresenta os hidrogéis sintetizados sem e com agitação magnética (4 rpm), após o processo de aquecimento $\left(100^{\circ} \mathrm{C}\right)$, destaca-se que o hidrogel teve que ser colocado em um recipiente de plástico antes de ser congelado, devido ao aumento significativo em seu volume e, assim evitar possíveis perdas das amostras. Enquanto, a Figura 3b ilustra o hidrogel não liofilizado após os processos de congelamento, descongelamento e recongelamento, indicando uma textura de uma esponja umedecida.

Figura 3 - (a) Hidrogéis de amido sintetizados sem e com agitação magnética, com aquecimento e

(b) Hidrogel pós os processos de congelamento, descongelamento e recongelamento.

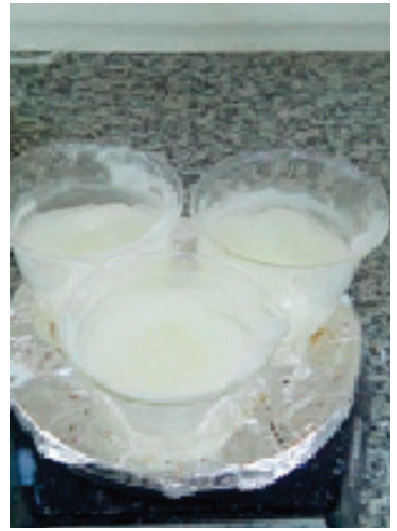

(a)

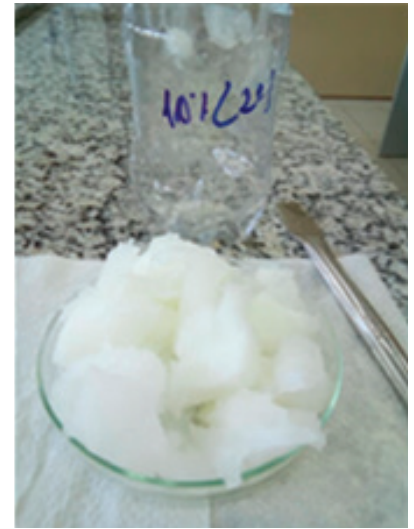

(b)

Fonte: Construção do Autor. 


\section{GRAU DE INTUMESCIMENTO}

A Tabela 2 apresenta o intumescimento em relação à massa seca (g) (Equação 2) e a percentagem (\%) do grau de intumescimento (Equação 3) dos hidrogéis sintetizados sem/com agitação magnética e sem/com o processo de liofilização.

Tabela 2 - Percentagem (\%) do grau de intumescimento e o intumescimento em relação à massa seca $(\mathrm{g})$ dos hidrogéis sintetizados liofilizados e não liofilizados com e sem agitação magnética $\left(\mathrm{m}_{2}=0,5 \mathrm{~g}\right)$.

\begin{tabular}{ccccc}
\hline Hidrogel & Tempo $(\mathbf{m i n})$ & Massa umedecida $\left.\mathbf{( m}_{\mathbf{1}}\right)$ & $\mathbf{Q}(\mathbf{\%})$ & $\mathbf{Q}(\mathbf{g})$ \\
\hline & 5 & $3,73 \pm 0,07$ & 646 & 7,46 \\
Não liofilizado/sem agitação & 10 & $3,76 \pm 0,04$ & 652 & 7,52 \\
& 15 & $3,77 \pm 0,03$ & 654 & 7,54 \\
& 60 & $3,93 \pm 0,01$ & 686 & 7,86 \\
Não liofilizado/com agitação & 5 & $3,83 \pm 0,05$ & 666 & 7,66 \\
& 10 & $3,87 \pm 0,01$ & 674 & 7,74 \\
& 15 & $3,91 \pm 0,03$ & 682 & 7,82 \\
Liofilizado/sem agitação & 60 & $3,92 \pm 0,03$ & 684 & 7,84 \\
& 5 & $5,37 \pm 0,02$ & 974 & 10,74 \\
& 10 & $5,46 \pm 0,01$ & 992 & 10,92 \\
& 15 & $5,63 \pm 0,02$ & 1.026 & 11,26 \\
Liofilizado/com agitação & 60 & $5,98 \pm 0,04$ & 1.096 & 11,96 \\
& 5 & $5,58 \pm 0,04$ & 1.016 & 11,16 \\
& 10 & $6,01 \pm 0,01$ & 1.102 & 12,02 \\
& 15 & $6,09 \pm 0,08$ & 1.118 & 12,18 \\
& 60 & $6,32 \pm 0,03$ & 1.164 & 12,64 \\
\hline
\end{tabular}

Fonte: Construção do Autor.

Conforme a Tabela 2, é possível verificar que o hidrogel de amido liofilizado e com agitação magnética apresentou a maior capacidade de absorção de água em relação aos demais hidrogéis, visto seus respectivos valores de intumescimento (entre 1.016\% - 1.164\%), com destaque para a amostra com o tempo de 60 minutos de imersão do hidrogel em água. Ligado a isto, esta elevada absorção de água, como um superabsorvente, contribui no melhoramento da capacidade de retenção da água do hidrogel e, assim permite um maior armazenamento da água e nutrientes do solo como reservas, permitindo um crescimento sustentado das plantas, por exemplo (HUI-MIN; YU, 2006; AZEVEDO et al., 2002)

Além disso, é possível verificar que o processo de liofilização promoveu um aumento no grau de intumescimento do hidrogel, sem ou com agitação magnética, durante a síntese. Por exemplo, considerando o tempo de imersão de 60 minutos, houve um incremento de 52,2\% e 61,2\% na capacidade de absorção de água dos hidrogéis sem agitação e com agitação, respectivamente. Isto é devido ao fato que a liofilização promove um aumento na área específica e espessura do hidrogel, visto que ocorre uma expansão física da estrutura polimérica e consequente exposição das regiões hidrofóbicas, que anteriormente se localizavam na região mais interior do polímero (hidrogel) (ALMEIDA, 2010; HENNINK; VAN NOSTRUM, 2002). Por conseguinte, maior será a taxa de difusão intermolecular 
da água dentro da amostra, proporcionando uma maior absorção da mesma e, assim um aumento no intumescimento do hidrogel (MA; ZHANG, 2001).

\section{TESTES DE GERMINAÇÃO}

Para os testes de germinação foram utilizadas sementes puras de soja e as revestidas com o hidrogel não liofilizado (Figura 4a), comparando com um hidrogel comercial. Assim, inicialmente as sementes foram alocadas nos papéis de germinação umedecidos (germitest), enroladas e posicionadas horizontalmente (Figura 4b). Em seguida, estes foram encaminhados para uma câmara de germinação e mantidos a temperatura de $26^{\circ} \mathrm{C}$, onde foram observadas diariamente. Entretanto, após o terceiro dia do teste de germinação verificou-se a presença de fungos, em ambas amostras, comprometendo totalmente o teste. Vale salientar que os papéis germitest passaram pelo ultrassom para a eliminação de qualquer contaminação.

Figura 4 - (a) Teste de germinação com sementes puras e revestidas com hidrogel não liofilizado e (b) sementes sob os papéis germitest, enroladas e em posição horizontal.

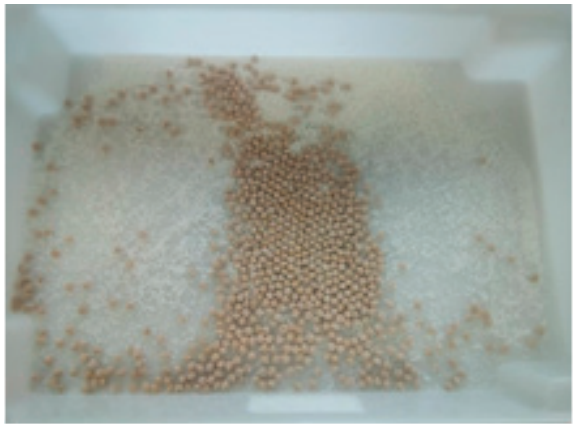

(a)

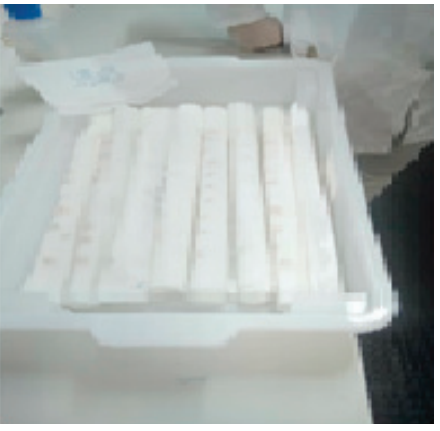

(b)

Fonte: Construção do Autor.

Destaca-se que os autores pretendem reavaliar o teste de germinação realizado, a fim de indicar quais as possíveis fontes dos erros e avaliar os possíveis fatores que afetam a germinação e o aparecimento de fungos, como fatores ambientais (como a quantidade e disponibilidade de água, radiação solar, quantidade de oxigênio) e qualidade da semente (como tamanho e uniformidade da semente, teor de umidade na semente), conforme literatura adequada (DUNLEAVY, 1976; FRANÇA NETO, 1984).

\section{CONCLUSÃO}

Com bases nos resultados apresentados, pode-se concluir que foi possível sintetizar hidrogéis de amido milho com características superabsorventes, conforme a elevada percentagem no grau de intumescimento e a considerável massa de amostra, com destaque para o hidrogel liofilizado preparado com agitação magnética (grau de intumescimento de cerca de $1.100 \%$ ). Além disso, verificou-se 
que os hidrogéis liofilizados apresentaram uma maior absorção de água, proporcionado pelo aumento da área específica e espessura das amostras e, assim aumento na taxa de difusão intermolecular da água sob o hidrogel. Tendo em vista que todos os hidrogéis sintetizados apresentaram características superabsorventes, ultrapassando $100 \%$ de retenção de água, optou-se pela utilização dos hidrogéis não liofilizados devido ao menor tempo de síntese e menor custo associado. Por conseguinte, novos testes de germinação devem ser realizados avaliando fatores ambientais e as características da semente de soja, bem como um comparativo com hidrogéis comerciais.

\section{AGRADECIMENTOS}

Os autores agradecem ao Núcleo Técnico Científico do Instituto de Ciência e Tecnologia de Alimentos (ICTA) da Universidade Federal do Rio Grande do Sul (UFRGS) pelo suporte e auxílio para realização do presente trabalho.

\section{REFERÊNCIAS}

ALMEIDA, J. F. Preparação e caracterização de hidrogéis para aplicações biomédicas. 2010. 308 p. Tese de Doutorado (Doutorado em Engenharia Química) - Faculdade de Ciência e Tecnologia, Universidade de Coimbra, Coimbra, 2010.

ARIETA, P. F. Caracterização de produtos comerciais à base de amido de milho. 2014.58 p. Monografia (Graduação em Engenharia dos Materiais) - Escola Politécnica, Universidade Federal do Rio de Janeiro, Rio de Janeiro, 2014.

AZEVEDO, T. L. F.; et al. Uso de hidrogel na agricultura. Revista do Programa de Ciências Agro-Ambientais, 2020, v. 1, p. 23-31.

BARCELLOS, C.; et al. Mudanças climáticas e ambientais e as doenças infecciosas: cenários e incertezas para o Brasil. Epidemiologia e Serviços de Saúde, 2009, v. 18, p. 285-304.

BARROS, A. F. Avaliação do potencial de uso de polímero superabsorvente no revestimento de sementes de sorgo. 2016. 56 p. Dissertação (Mestrado em Fitotecnia) - Programa de Pós-Graduação em Fitotecnia, Universidade Federal de Viçosa, Minas Gerais, 2016. 
BAUDET, L.; PESKE, S. T. A logística do tratamento de sementes. Seed News, 2006, v. 10, p. 20-23.

BRANT, A. J. D. Preparação e caracterização de hidrogéis a partir de misturas de soluções de quitosana e poli(N-vinil-2-pirrolidona). 2008. 170 p. Tese de Doutorado (Doutorado em Química Orgânica) - Programa de Pós-Graduação em Química, Universidade de São Paulo, São Paulo, 2008.

DALL'AGNOL, A. Grandes produtores e consumidores de alimentos. 2017. Disponível em: https://bit.ly/2EL1O0i. Acesso em: 10 mai. 2018.

DOMENECH, S. C.; et al. Characterization, morphology, thermal and mechanical properties of conductive polyaniline-functionalized EPDM elastomers obtained by casting. Journal of Polymer Science Part B: Polymer Physics, 2004, v. 42, p. 1767-1782.

DOMICIANO, M. G.; et al. Hidrogéis para retenção e disponibilização de água para cultivos agrícolas. Revista Brasileira de Pesquisa em Alimentos, 2010, v. 1, p.121-124.

DUNLEAVY, J. M. Pathological factors affecting seed germination In: World soybean research. Dauville, 1976, p.462-469.

FLOSS, E. L.; FLOSS, L. G. Fertilizantes organominerais de última geração: funções fisiológicas e uso na agricultura. Revista Plantio Direto, n. 100, 2007. Disponível em: https://bit.ly/3keVQCH. Acesso em: 27 mai. 2018.

FRANÇA NETO, J .B. Qualidade fisiológica da semente. In: Qualidade fisiológica e sanitária de sementes de soja. Londrina, 1984, p. 1-24.

GUILHERME, M. R.; et al. Superabsorbent hydrogels based on polysaccharides for application in agriculture as soil conditioner and nutrient carrier: A review. European Polymer Journal, 2015, v. 72 , p. $365-385$.

HENNINK, W. E.; VAN NOSTRUM, C. F. Novel crosslinking methods to design hydrogels. Advanced Drug Delivery Reviews, 2002, v. 54, p. 13-36.

HUI-MIN, T.; YU, C. Crosslinked carboxymethylchitosan-g-poly(acrylic acid) copolymer as a novel superabsorbent polymer. Carbohydrate Research, 2006, v. 341, p. 887-896. 
LI; M.; TSHABALALA; M. A.; BUSCHLE-DILLER, G. Formulation and characterization of polysaccharide beads for controlled release of plant growth regulators. Journal of Materials Science, 2016, v. 51, p. 4609-4617.

LIMA, A. P. D. Síntese e caracterização de hidrogéis compósitos superabsorventes a base de poliacrilamida e vermiculita. 2008. 95 p. Dissertação (Mestrado em Química Inorgânica) - Programa de Pós-Graduação em Química Inorgânica, Universidade Federal do Ceará, Fortaleza, 2008.

LOPES, A. L. C. Dossiê técnico: Cultivo e manejo da soja. Serviço Brasileiro de Respostas Técnicas, 2013, v. 1, p. 1-37.

MA, P. X.; ZHANG, R. Microtubular architecture of biodegradable polymer scaffolds. Journal of Biomedical Materials Research, 2001, v. 56, p. 469-477.

MAPA - MINISTÉRIO DAAGRICULTURA, PECUÁRIA E ABASTECIMENTO. Manual de regras de análise de sementes. 2009. Disponível em: https://bit.ly/33wJyQa. Acesso em: 15 mai. 2018.

MOTTA, C. Preparação e caracterização de hidrogéis superabsorventes a partir de quitosana e poliacrilonitrila. 2009. 31p. Relatório final de estágio - Centro de Ciências Físicas e Matemáticas Departamento de Química, Universidade Federal de Santa Catarina, Florianópolis, 2009.

NETO, F; et al. O estudo de viabilidade e eficiência do uso do hidrogel no desenvolvimento do feijão. Revista Brasileira de Ciências Agrárias, 2012, v. 7, p. 548-554.

PEREIRA, C. E.; et al. Qualidade fisiológica de sementes de milho tratadas associadas a polímeros durante o armazenamento. Ciência e Agrotecnologia, 2005, v. 29, n. 6, p. 1201-1208.

PRETTO, R.; et al. A Tecnologia do hidrogel na eficiência de uso do nitrogênio sobre a produtividade de biomassa e grãos de trigo em sistema de rápida liberação de N-residual. In: Seminário de Inovação e Tecnologia - Salão do Conhecimento: Ciência Alimentando o Brasil, 2016, São Paulo. Anais. Unijuí: 2016. 
YONEZAWA, U. G. Síntese, caracterização e aplicação de hidrogéis nanoestruturados contendo nanoargila para melhorar a germinação e qualidade de muda de hortaliça. 2016. 101 p. Dissertação (Mestrado em Ciência dos Materiais) - Programa de Pós-Graduação em Ciências dos Materiais, Universidade Estadual Paulista, São Paulo, 2016.

YONEZAWA, U. G.; MOURA, M. R.; AOUADA, F. A. Estado da arte: um estudo sobre polímeros biodegradáveis na germinação e desenvolvimento de plantas. Caderno de Ciências Agrárias, 2017, v. 9 , n. 2 , p. $69-78$. 
